\title{
Splicing arrays reveal novel RBM10 targets, including SMN2 pre-mRNA
}

\author{
Leslie C. Sutherland ${ }^{1,2,3^{*}} \mathbb{0}$, Philippe Thibault ${ }^{4}$, Mathieu Durand ${ }^{4}$, Elvy Lapointe ${ }^{4}$, Jose M. Knee ${ }^{1}$, \\ Ariane Beauvais ${ }^{5}$, Irina Kalatskaya ${ }^{6}$, Sarah C. Hunt ${ }^{3}$, Julie J. Loiselle², Justin G. Roy ${ }^{3}$, Sarah J. Tessier ${ }^{1}$, \\ Gustavo Ybazeta', Lincoln Stein ${ }^{6}$, Rashmi Kothary ${ }^{5,7}$, Roscoe Klinck ${ }^{4,8}$ and Benoit Chabot ${ }^{8}$
}

\begin{abstract}
Background: RBM10 is an RNA binding protein involved in message stabilization and alternative splicing regulation. The objective of the research described herein was to identify novel targets of RBM10-regulated splicing. To accomplish this, we downregulated RBM10 in human cell lines, using small interfering RNAs, then monitored alternative splicing, using a reverse transcription-PCR screening platform.

Results: RBM10 knockdown (KD) provoked alterations in splicing events in 10-20\% of the pre-mRNAs, most of which had not been previously identified as RBM10 targets. Hierarchical clustering of the genes affected by RBM10 KD revealed good conservation of alternative exon inclusion or exclusion across cell lines. Pathway annotation showed RAS signaling to be most affected by RBM10 KD. Of particular interest was the finding that splicing of SMN pre-mRNA, encoding the survival of motor neuron (SMN) protein, was influenced by RBM10 KD. Inhibition of RBM10 resulted in preferential expression of the full-length, exon 7 retaining, SMN transcript in four cancer cell lines and one normal skin fibroblast cell line. SMN protein is expressed from two genes, SMN1 and SMN2, but the SMN1 gene is homozygously disrupted in people with spinal muscular atrophy; as a consequence, all of the SMN that is expressed in people with this disease is from the SMN2 gene. Expression analyses using primary fibroblasts from control, carrier and spinal muscle atrophy donors demonstrated that RBM10 KD resulted in preferential expression of the full-length, exon 7 retaining, SMN2 transcript. At the protein level, upregulation of the full-length SMN2 was also observed. Re-expression of RBM10, in a stable RBM10 KD cancer cell line, correlated with a reversion of the KD effect, demonstrating specificity.
\end{abstract}

Conclusion: Our work has not only expanded the number of pre-mRNA targets for RBM10, but identified RBM10 as a novel regulator of SMN2 alternative inclusion.

Keywords: RBM10, SMN2, Alternative splicing, Splicing array, Spinal muscular atrophy, Cancer

\section{Background}

RNA Binding Motif 10 (RBM10) is an RNA binding protein that has an arginine-rich amino terminal, two RNA Recognition Motifs (RRMs), a $\mathrm{C}_{2} \mathrm{H}_{2}$ zinc finger, a RanBP2 zinc finger, an OCtamer REpeat element and a G-patch [1]. It binds to a number of RNA targets, including sequences encoding NUMB [2], RBM5 and other RNA binding proteins [3]. Functionally, overexpressed RBM10 causes apoptosis, and low levels of RBM10 are associated

\footnotetext{
*Correspondence: Isutherland@hsnri.ca

${ }^{1}$ Health Sciences North Research Institute, Sudbury, ON P3E 5J1, Canada Full list of author information is available at the end of the article
}

with decreased sensitivity to an apoptogenic stimulus [4], and increased colony formation [2]. Mechanistically, RBM10 is involved in mRNA stabilization [5] and regulation of alternative splicing [2, 3, 6-8].

From a systemic point of view, expression of $R B M 10$ is vital for normal embryonic development. Null mutations in RBM10 affect development of the brain, face, heart, lungs, kidneys, limbs and central nervous system during early embryogenesis: the most aggressive phenotypic manifestation of null RBM10 mutation is TARP syndrome (comprising Talipes equinovarus, atrial septal defect, Robin sequence and cleft palate), an X-linked recessive disorder that results in early 
mortality-predominantly as a result of heart conduction defects $[9,10]$. Changes in alternative splicing of the pre-mRNA from key target genes may be how mutated RBM10 contributes to TARP syndrome [3]. Expression of RBM10 is also important for tumor suppression [11], and reduced expression has been observed in pancreatic cancer [12] and non-small cell lung carcinoma [13]. Paradoxically, expression of RBM10 (like its paralogue, the tumor suppressor RBM5) is elevated in some cancers, such as multiple endocrine neoplasia type 1 [14], breast cancers [15], liver and colon cancers [16] and some metastatic melanomas [17]. Elevated expression may be related to upregulation of pro-apoptotic signaling pathways triggered by cancer-related abnormalities, such as uncontrolled proliferation, but the definitive reason for this elevation is unknown.

Since RBM10 is a tumour suppressor, and the regulation of alternative splicing is an important process that is deregulated in cancer [18-20], we set out to identify novel RBM10-regulated alternative splicing events using cancer cell lines. We used siRNAs to inhibit RBM10 expression in two ovarian, two breast and one prostate cancer cell line(s), as well as one non-cancer cell line. We examined arrays of alternative splicing events (ASEs) using a reverse transcription-PCR screening platform [21]. An SMN ASE was the focus of more detailed expression analyses, at both the RNA and protein levels, in primary fibroblasts and a breast cancer cell line with stable RBM10 knockdown (KD). Our results indicated that RBM10 was capable of regulating the expression of SMN2 RNA and protein, RBM10 inhibition correlating with increased expression of the full-length $S M N 2$ RNA and protein. These results suggest that RBM10 functions as an inhibitor of $S M N 2$ exon 7 splicing.

\section{Methods}

\section{Cell lines}

Epithelial adenocarcinoma cell lines were from breast (MCF-7 and MDA-MB-231), ovary (SKOV-3 and NIH:OVCAR-3) and prostate (PC-3), and the fibroblastic normal cell line was from skin (BJT). Cells were grown in Dulbecco modified eagle medium (DMEM) (MCF7, MDA-MB-231, SKOV-3, NIH:OVCAR-3), Ham F-12 medium (PC-3) or alpha-minimal essential medium (BJT), all supplemented with $10 \%$ fetal bovine serum (FBS). The MCF-7 cell line with stable RBM10 KD was generated as previously described [4].

\section{Splicing arrays}

In the cell lines used for the splicing arrays, RBM10 KD was achieved using two distinct and non-overlapping siRNAs: RBM10 siRNA1 (exon 7) 5'-AAG GUG UCG AUG CAC UAC A-3'; RBM10 siRNA2 (exon 23) 5'-GCA UUG
UAA CGC CUA UCG A-3', purchased from Dharmacon (Cedarlane, Burlington, Canada). siRNAs were transiently transfected as previously described [21]. RBM10 expression inhibition (KD) was assessed for the splicing arrays by immunoblotting, $96 \mathrm{~h}$ post-transfection, using a rabbit anti-RBM10 primary antibody (Cedarlane Laboratories Ltd; ARP30103), a rabbit anti-ACTIN primary antibody (Sigma; A2066) (for protein normalization) and a goat HRP-conjugated anti-rabbit secondary antibody (GE Life Sciences; NA934).

RT-PCR assays for the siRNA experiments were carried out as previously described [21]. The data can be accessed at http://rnomics.med.usherbrooke.ca/ palace?purl=pcrreactiongroup $/$ list $/ 299$. The list of genes and primers can be found on-line (http://rnomics.med. usherbrooke.ca/palace?purl=data/related/2495) (Additional file 1). Visualization and analysis of amplified products was carried out using the LabChip HT DNA Assay on an automated microfluidic station (Caliper, Hopkinton, MA, USA).

\section{Alternative splicing analysis}

Primer sequences used in RT-PCR assays to (a) confirm the ASEs observed in the splicing arrays and (b) investigate SMN alternative splicing in the fibroblasts, were the same as those used in the splicing arrays (AlphaDNA, Montreal, $\mathrm{PQ}$ ). RBM10 primers used to confirm KD in fibroblasts and MCF-7 cells (RBM10F and RBM10v1/ v2R), and control ACTIN (actinF and actinR) primers, were as previously described $[4,15]$. PCR amplification conditions for RBM10 were as previously described [15]. PCR amplification conditions for SMN2 and actin were $95{ }^{\circ} \mathrm{C} 4 \mathrm{~min}$, followed by 40 cycles $(S M N)$ or 25 cycles (ACTIN) of $95{ }^{\circ} \mathrm{C} 30 \mathrm{~s}, 59^{\circ} \mathrm{C}(S M N)$ or $67{ }^{\circ} \mathrm{C}($ ACTIN) $30 \mathrm{~s}, 72{ }^{\circ} \mathrm{C} 30 \mathrm{~s}$, followed by $72{ }^{\circ} \mathrm{C}$ for $10 \mathrm{~min}$.

\section{Hierarchical clustering analysis}

Genes with a change in at least one cell line were subjected to two-way unsupervised hierarchical clustering using the R package 'pheatmap'. Hierarchical clustering analysis was done using Euclidean distance and either average or ward.D linkage. Pathway enrichment analysis was carried out using an in-house tool based on pathways downloaded from Reactome (release 55), the latest version of KEGG (November 2015), BioCarte (January 2012) and Panther (version 3.0.1).

\section{Human fibroblast analyses}

Primary human fibroblasts: control (GM08333), carrier (NA03814) and SMA Type 1 (NA03813) (Coriell Institute for Medical Research, Camden, New Jersey, USA) were grown in DMEM supplemented with 15\% FBS. All media and supplements were purchased from Life Technologies 
(Burlington, Canada). The passage numbers of fibroblasts used in the transient RBM10 KD studies were: control 6-9, carrier 11-14, and SMA Type 1 8-12. RBM10 KD was achieved using siRNA2 (to exon 23) (Thermo Fisher Scientific, Waltham, MA, USA).

\section{Immunoblotting}

Protein expression in fibroblasts was examined by Western blotting. A mouse anti-SMN antibody was used (1:20,000 dilution; Cat. No. 610647, BD Biosciences, Mississauga, Canada) with either (1) a near infra-red fluorescent dye (IRDye 680RD) conjugated goat anti-mouse IgG (Li-COR, Lincoln, NE, USA) for in-gel probing using the Odyssey CLx Imaging System, or (2) an HRP-conjugated goat anti-mouse IgG (1:10,000 dilution, Santa-Cruz Biotechnology, Inc., Dallas, Texas, USA) for film-captured chemiluminescence and quantification using the densitometry tool on the AlphaEaseFC Gel Imaging System (Alpha Innotech, San Leandro, CA, USA). A rabbit anti-RBM10 antibody (1:5000 dilution, ProteinTech, Rosemont, IL, USA), and a rabbit anti- $\beta$-ACTIN antibody (1:10,000 dilution; Novus Biologicals, Littleton, CO, USA), were used with a goat anti-rabbit HRP-conjugated secondary antibody (1:10,000 dilution; Santa-Cruz Biotechnology).

\section{Results}

To identify novel alternative splicing events associated with RBM10 inhibition we used splicing arrays that incorporated RNA from cell lines either mock transfected or individually transfected with two non-overlapping RBM10-specific siRNAs, and primers with the potential to yield two amplicons of between 150 and 700 bp (for adequate resolution by microfluidic analysis). For each ASE, a percent splicing index change $(\Delta \psi)$ was calculated as the shift in splice site selection based on the difference between the $\psi$ obtained with a given siRNA and the $\psi$ obtained from the control transfection performed on the same day. A change was defined as the $\Delta \psi$ of eight percentage points or more, a threshold value that was based on [Z]-scores for control reactions performed with the ASEs in previous studies [21]. We added the further requirement that both siRNAs must produce a shift in the same direction (i.e., exon exclusion or exon inclusion).

\section{$29 \%$ of 96 cancer-related ASEs were changed in one or more of five cancer cell lines upon RBM10 KD}

We initially examined predominantly cancer-associated genes known to have ASEs that change between normal and cancer tissues. This initial screen consisted of 96 ASEs from 92 genes (see below for link to data with list of genes). RNA from five cancer cell lines (MCF-7, MDA-MB-231, SKOV-3, OVCAR-3 and PC-3) was used. Representative electropherogram data, from the capillary electrophoresis of specific ASEs in individual cell lines with one siRNA, can be seen in Fig. 1 .

The results for this screen of 96 ASEs in five cell lines (termed Array-96) demonstrated that 28/96 ASEs (29\%) were changed in one or more cell line(s) (http://rnomics.med.usherbrooke.ca/palace?purl=data/related/1811) (Additional file 2), with approximately $18 \%$ (5/28 of the genes examined, namely AFF3, FN1, KITLG, SRP19 and SYNE2) being changed in $\geq 3 / 5$ cell lines (Fig. 2; Additional file 3: Table S1 for an alphabetised listing of ASEs). Knockdown of RBM10 was, therefore, associated with changed ASEs in cancer cell lines.

Almost 68\% (19/28) of the changes occurring in one or more cell line(s) involved exon inclusion in the RBM10 $\mathrm{KD}$, while within the cluster of changes common to three or more cell lines (AFF3, FN1b, KITLG, SRP19 and $S Y N E 2$ ) only SRP19 did not involve exon inclusion in the KD. Refer to Fig. 1 for representative electropherograms of FN1b and KITLG.

Interestingly, both of the ovarian cancer cell lines (OVCAR-3 and SKOV-3) experienced more changes than either of the two breast cancer (MCF-7 and MDAMB-231) or one prostate cancer (PC-3) cell lines (at 15 and 12 versus 7, 6 and 6 , respectively). When we applied unsupervised hierarchical clustering analysis to look for patterns in cell line association, however, while the data showed a good separation of the 28 changes into two major clusters-those consistently experiencing preferential exon exclusion associated with RBM10 $\mathrm{KD}$, and those consistently experiencing preferential exon inclusion associated with RBM10 KD, there was no clustering of changes to either ovarian cancers or breast cancers (Fig. 2). This finding suggests that the regulation of these ASEs by RBM10 was not cancertype specific.

(See figure on next page.)

Fig. 1 Electropherogram results for KITLG and FN1b ASEs from Array-96 and for SMN2 and SIAHBP1 ASEs from Array-191. The electropherograms on the left are from the control transfections using scrambled siRNA, while the electropherograms on the right are from the RBM $10 \mathrm{KD}$ transfections using the siRNA indicated. Each row represents the results from the cell line indicated. The "expected" amplicon size is shown below the electropherogram, while the "found" amplicon size is shown above 


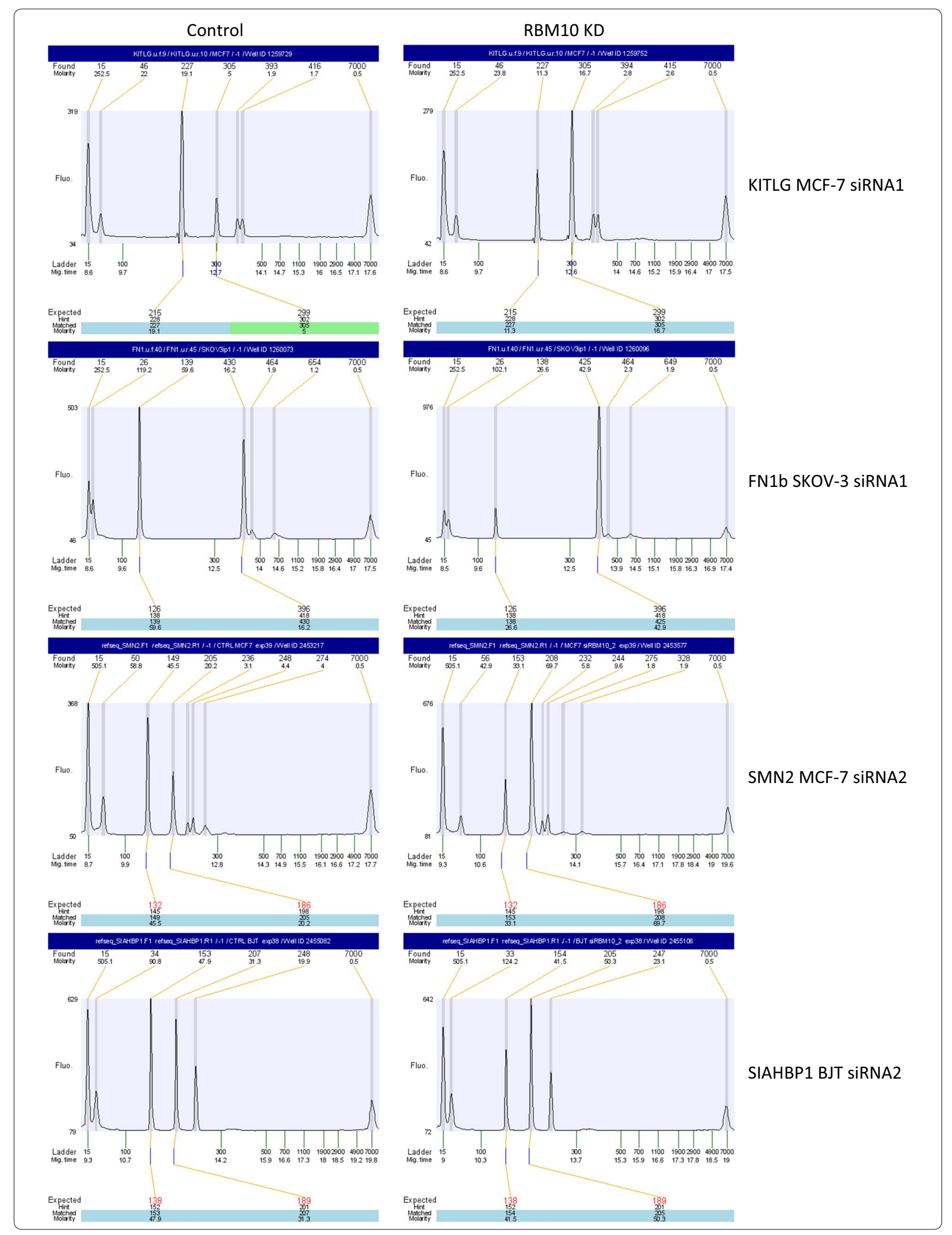




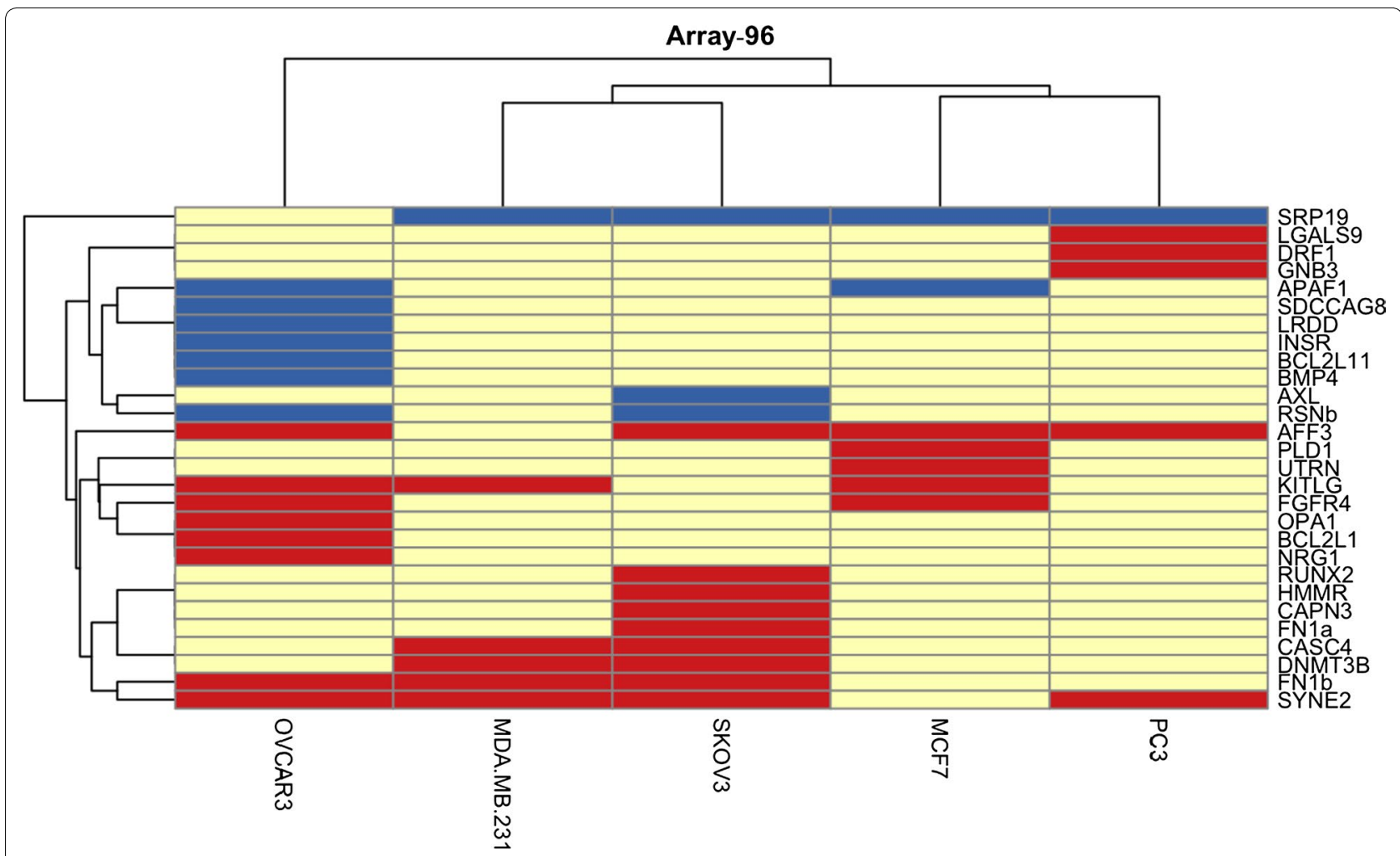

Fig. 2 Heatmap and unsupervised hierarchical clustering of genes changed in Array-96 and cell lines used (built using R package 'pheatmap'). Each row represents the gene that had a change in at least one cell line, and each column represents the cell line used in the experiment. Preferential exon exclusion shown in blue; preferential exon inclusion shown in red. The Euclidean distance metric was used for clustering, while the linkage method used was "average" linkage

$60 \%$ of 191 pre-selected ASEs were changed in one or more of four cancer cell lines and one non-cancer cell line upon RBM10 KD

Splicing changes associated with RBM10 KD were next examined in a larger pool (involving 184 genes and 191 ASEs). These units corresponded to a selection of the best events from previous RT-PCR screenings in 10 different cell lines that displayed good yield and reproducibility [22], with $8.3 \%$ overlap to the ASEs queried in Array-96. The 191 ASEs were investigated in RNA from the previous RBM10 KDs in the MCF-7, MDA-MB-231, PC-3, SKOV-3 (the same used for Array-96, excluding OVCAR-3) and a new transient RBM10 KD in the nontumorigenic immortalized fibroblast cell line BJT. This screen was termed Array-191 [http://rnomics.med.usherbrooke.ca/palace?purl=data/related/2493 (Additional file 4)-termed 'Array-192' on-line, but the two sets of SMN2 primers were subsequently found to amplify the same ASE]. The percentage of RBM10 KD, in the two transfections of each cell line used in Array-96 and Array-191, is summarized in Table 1.

As shown in Fig. 3 (and in Additional file 5: Table S2, as an alphabetised listing of ASEs), 115 of the 191 ASEs (60\%)
Table 1 Percentage of RBM10 KD in two transfections of each cell line, $96 \mathrm{~h}$ post transfection

\begin{tabular}{lll}
\hline Cell line & Transfection & \% KD RBM10 protein \\
\hline MCF-7 & siRNA1 & 67 \\
MDA-MB-231 & siRNA2 & 60 \\
& siRNA1 & 53 \\
NIH:OVCAR-3 & SiRNA2 & 80 \\
& SiRNA1 & 55 \\
PC-3 & SiRNA2 & 80 \\
& siRNA1 & 67 \\
SKOV-3 & SiRNA2 & 90 \\
& SiRNA1 & 80 \\
& SiRNA2 & 93 \\
\hline
\end{tabular}

were changes in one or more cell line(s), with approximately $12 \%$ (14/115) occurring in $\geq 3 / 5$ cell lines (more clearly illustrated in Fig. 4). 78.5\% (11/14) of the knockdown-induced changes occurring in three or more cell lines involved exon inclusion. As seen in Fig. 4, three of the 14 changes (in C5orf5/FAM13B, SIAHBP1 and SMN2) occurred in all five cell lines. Refer to Fig. 1 for representative electropherograms of SMN2 and SIAHBP1. 


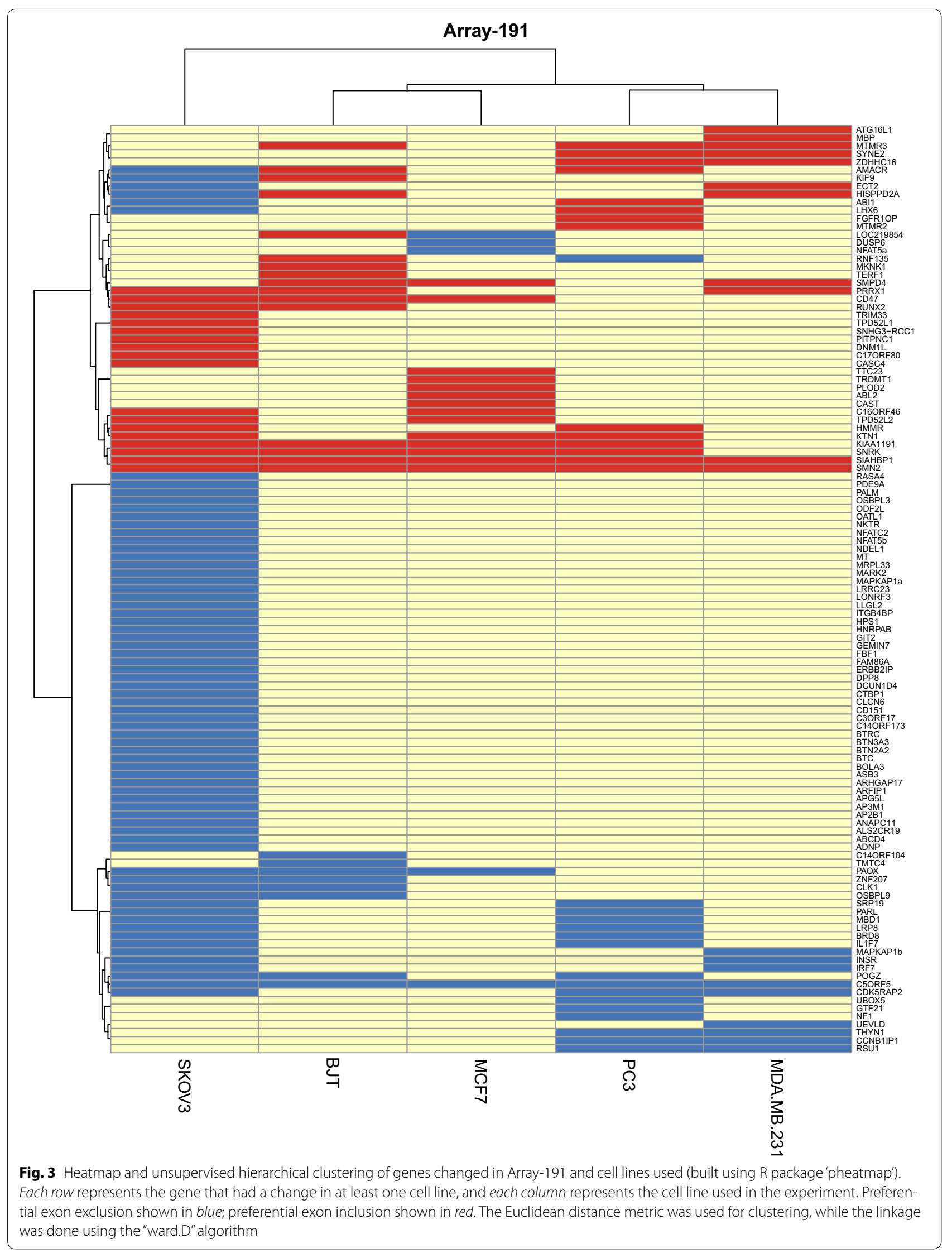




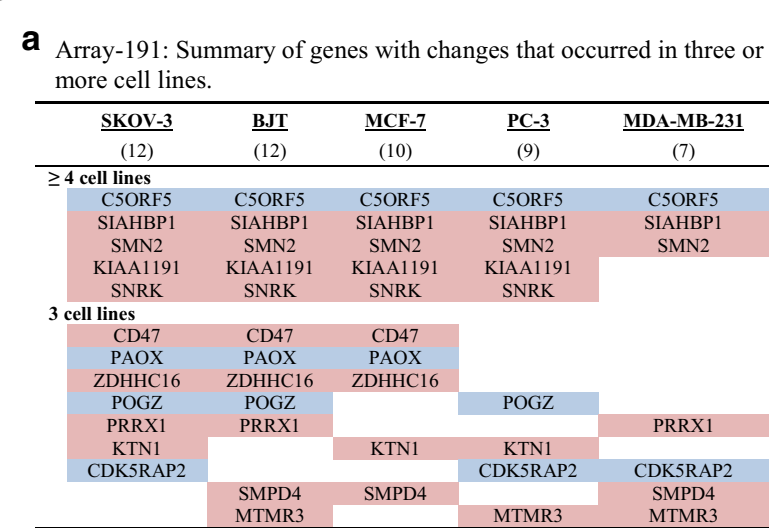

Red signifies an inclusion event, blue signifies an exclusion event.

b

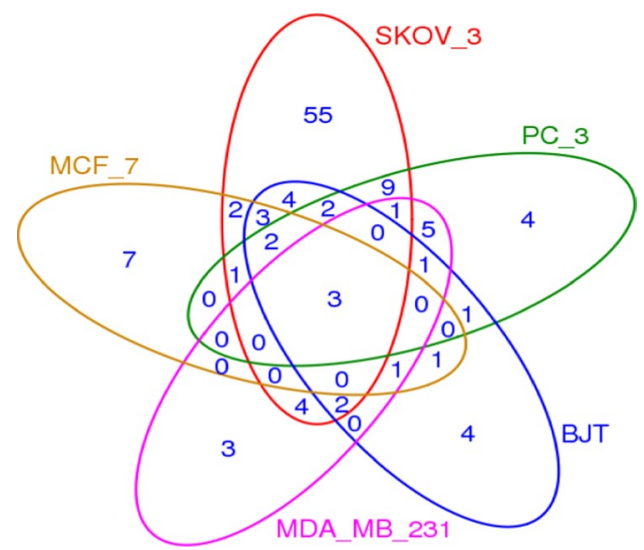

Fig. 4 Changes associated with RBM10 KD in Array-191. a Venn diagram showing the relative distribution of changes amongst the five cell lines. Modified from http://faculty.ucr.edu/ tgirke/Documents/R. b Summary of changes, by cell line, that occurred in three or more cell lines

Hierarchical clustering analysis (Fig. 3) revealed that $12.5 \%(3 / 24)$ of the changes occurring in the BJT cells and only one other cancer cell line (in genes KIF9, LOC219854/TMEM218 and RNF135) showed a shift in the BJT cells opposite to that which occurred in the cancer cells; however, in each of the three instances, preferential exon exclusion was seen in the cancer cells, but preferential exon inclusion in the BJT cells. Unfortunately, whether or not these differences relate to noncancer versus cancer, skin versus other tissue type, or fibroblast versus epithelial cell, cannot be determined from the limited number of cell lines examined. The fact that as many changes occurred in the non-cancer cell line (24) as some of the cancer cell lines, e.g., MCF-7 (19), MDA-MB-231 (20) and PC3 (30), did demonstrate, however, that the regulatory effect of RBM10 on alternative splicing was not restricted to cancer cells.
Confirmation of transient RBM10 KD-associated changes in alternative splicing using a stable RBM10 KD human breast cancer cell line

For a previous study, we had generated a stable RBM10 KD MCF-7 human breast cancer subline [4]. We decided to use this stable RBM10 KD subline to confirm the effect of downregulated RBM10 on specific ASEs.

Focusing on five of the ten changes that occurred specifically in the MCF-7 cells of Array-191, and in two or more of the other cell lines (as listed in Fig. 4a: namely SIAHBP1/PUF60, SMN2, KIAA1191, POAX and $S M P D 4)$, we demonstrated that the alternative splicing changes that occurred in the transient RBM10 KD cells also occurred in the stable RBM10 KD MCF-7 cells [4] (Additional file 6). A relationship between reduced RBM10 expression levels and altered splicing of specific pre-mRNA transcripts was therefore confirmed using a slightly different model system.

\section{Alternative splicing of RAS-signaling-associated genes is significantly affected by RBM10 KD}

We next carried out pathway analysis of the 125 changes that occurred in only those cell lines that were common to both Array-96 and Array-191 (therefore excluding the changes unique to OVCAR-3 in Array-96 and BJT in Array-191), from 259 ASEs examined (Additional file 7: Table S3). The analysis revealed a significant effect of RBM10 KD on RAS signaling, since of the 13 RAS signaling pathway associated genes that were represented in the combined array ASE pool, five (ABL2, FGF4, GNB3, KITLG and PLD1) occurring within one hierarchical cluster were changed $(p=0.02)$. Since RAS signaling occurs in all cell types, and is fundamental to many processes-including cell proliferation, differentiation and survival-these results suggested that changes in RBM10 expression levels could impact most, if not all, cell types.

\section{In human fibroblasts, RBM10 KD correlated} with preferential SMN exon 7 inclusion at the RNA level One of the RBM10 KD-associated changes that was common to all five of the cell lines used in Array-191 occurred in SMN pre-mRNA. RBM10 KD consistently correlated with preferential SMN exon 7 inclusion, which is associated with the full-length $\mathrm{SMN}\left(\mathrm{SMN}^{\mathrm{FL}}\right)$ protein. There are two copies of the SMN gene in primates, telomeric SMN1 and the almost identical centromeric SMN2. While the two genes encode identical full-length $\mathrm{SMN}^{\mathrm{FL}}$, SMN2 predominantly codes for a truncated version, $\mathrm{SMN}^{\Delta 7}$. This truncated version results from a single nucleotide transition, in SMN2 exon 7, that inhibits splicing of the exon into the pre-mRNA. In people with the disease spinal muscular atrophy (SMA), both alleles of 
SMN1 are non-functional, but increased levels of $\mathrm{SMN}^{\mathrm{FL}}$, usually resulting from $S M N 2$ gene duplication, correlate with longer survival times [23]. Considering the importance of SMN ${ }^{\mathrm{FL}}$ levels to people with SMA, we therefore decided to examine the impact of RBM10 KD on SMN2 pre-mRNA alternative splicing in fibroblasts from donors with SMA. Based on our splicing array results, we anticipated that RBM10 KD would correlate with an increased ratio of the SMN2 exon 7-retaining transcript to the exon 7-lacking transcript.

We would like to note here that in Array-191, there were ASEs designated SMN1 and SMN2. The SMN1 ASE related to exon 5, whereas the SMN2 ASE related to exon 7. Since the coding regions of SMN1 and SMN2 are almost identical, the primers for all of the SMN ASEs should recognize both SMN1 and SMN2 sequences. At the time of primer design for the splicing arrays, alternative splicing of exon 7 was noted as being unique to SMN2 pre-mRNA (http://rnomics.med.usherbrooke.ca/ palace? purl=data/related/2495) (Additional file 1). The current Ensembl database (http://www.emsembl.org), however, shows that alternative splicing of exon 7 occurs in both SMN1 and SMN2 pre-mRNAs. That is why, unless we are specifically referring to our results from the SMA fibroblasts (which only contain SMN2), we do not refer to the SMN exon 7 ASE as an SMN2 ASE.

$S M N$ exon 7 splicing was examined in control, carrier and SMA Type 1 human fibroblasts. Firstly, we examined endogenous levels of SMN and RBM10 mRNA. As expected, and as shown in Fig. 5a, fibroblasts with wildtype $S M N 1$ alleles expressed almost exclusively $S M N$ exon 7 retaining transcript, fibroblasts from an SMA carrier (which lack one functional SMN1 allele) expressed both the exon 7 inclusion and exclusion variants, while fibroblasts from an SMA Type 1 patient (which lack both functional SMN1 alleles) predominantly expressed the exon 7 exclusion variant (encoded by SMN2). To note, the additional higher molecular weight SMN band, most clearly observed in the carrier and SMA Type 1 patient samples, is most likely a recently identified splice variant of both SMN1 and SMN2 that excludes exon 7 (54 nts) but includes an exon designated 6B (109 nts), termed SMN6B 4 [24]. Also, RBM10v1 and RBM10v2 were expressed in all of the fibroblasts.

As occurred in the splicing arrays, transient inhibition of RBM10 correlated with increased expression of the $S M N$ exon 7 inclusion RNA variant and decreased expression of the SMN exon 7 exclusion variant, in all of the fibroblasts (Fig. 5b, c). Changes in expression of SMN6B $\Delta 7$ were not noted. Data from 48 and $72 \mathrm{~h}$ postRBM10 KD were included to show that in the wt and carrier cells, greater RBM10 KD (at $72 \mathrm{~h}$ compared to $48 \mathrm{~h}$ ) correlated with an increased percentage of the $S M N$ inclusion variant. It was because the levels of $S M N$ inclusion appeared to correlate with the degree of RBM10 KD, and the degree of RBM10 KD differed between transfections, that the results in Fig. 5 are presented from individual, rather than combined, transfections. Overall, however, our results demonstrate that inhibition of RBM10 expression in human fibroblasts correlates with preferential SMN exon 7 inclusion at the RNA level.

\section{In human fibroblasts, RBM10 KD correlated} with preferential SMN exon 7 inclusion at the protein level Since the level of full-length SMN2 protein in people with SMA is the determinant of SMA severity, we extended our study to see if RBM10 KD correlated with increased $\mathrm{SMN}^{\mathrm{FL}}$ protein levels, in addition to preferential expression of the exon 7 inclusion RNA variant. As seen in Fig. 6, one SMN band $\left(\mathrm{SMN}^{\mathrm{FL}}\right)$ was detected in all the fibroblasts: this result was not unexpected, since the truncated SMN protein $\left(\mathrm{SMN}^{\Delta 7}\right)$ that is encoded by the SMN exon 7 exclusion variant is an unstable protein [25]. Densitometric analysis of the protein expression data, from four transfections, did, however, reveal a significant increase in the level of SMN ${ }^{\mathrm{FL}}$ in the SMA Type 1 fibroblasts, following RBM10 KD (Fig. 6). We did note that, at the protein level, only an almost total lack of RBM10 expression correlated with an increase in $\mathrm{SMN}^{\mathrm{FL}}$ protein expression levels that was statistically significant, suggesting that even small quantities of RBM10 protein are capable of interfering with $S M N$ exon 7 inclusion.

\section{Confirmation of RBM10 KD-associated preferential SMN exon 7 inclusion using a stable RBM10 KD human breast cancer cell line}

To further characterize the relationship between RBM10 and SMN expression, we decided to use our MCF-7 breast cancer subline with the stable RBM10 KD. Interestingly, both the control and RBM10 KD MCF-7 cells expressed the SMN exon 7 exclusion variant, the exon 7 inclusion variant, and what is likely the exon $6 \mathrm{~B} \Delta 7$ variant (Fig. 7). The control cells, however, showed preferential SMN exon 7 exclusion, whereas the RBM10 KD cells showed preferential SMN exon 7 inclusion (Fig. 7a).

Importantly, re-expression of RBM10, following transient transfection of RBM10v1 back into the stable RBM10 KD MCF-7 subline, reverted the splicing change induced by RBM10 KD, resulting in a decreased ratio of $S M N$ inclusion to exclusion variant expression (Fig. 7b). This result demonstrates that the altered SMN splicing associated with inhibition of RBM10 is indeed a direct result of the change in RBM10 expression levels.

At the protein level, surprisingly, a second band was observed (Fig. 7ci), a band that could represent an uncharacteristically stable $\mathrm{SMN}^{\Delta 7}$, since the ratio 
a $\mathbf{i}$

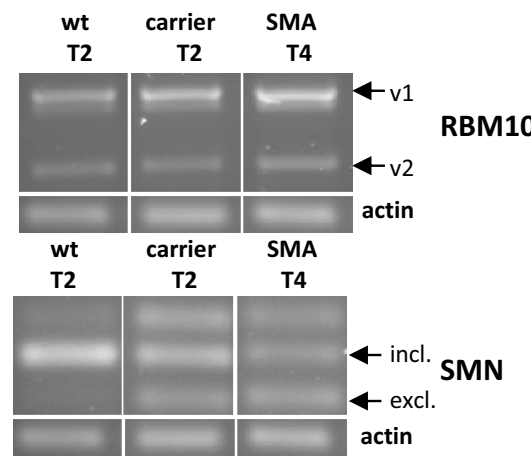

b i

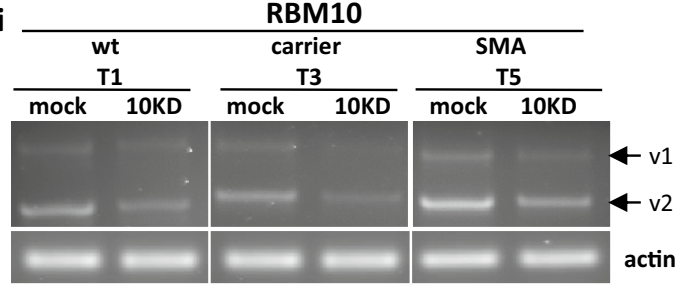

ii

RNA levels in parental fibroblasts

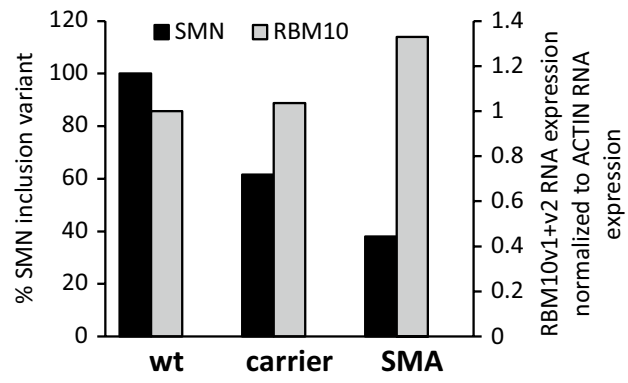

ii

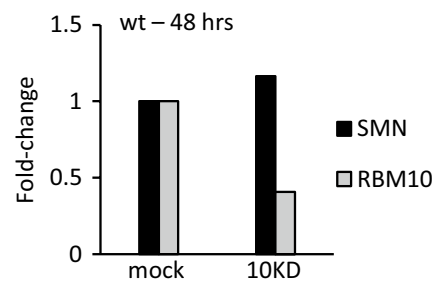

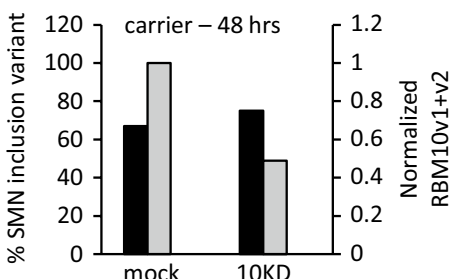

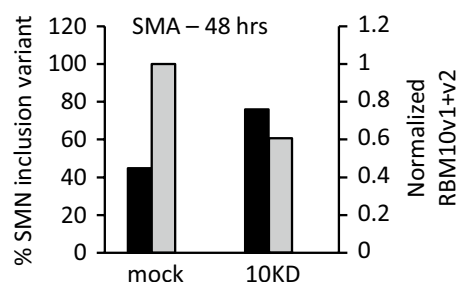

c i
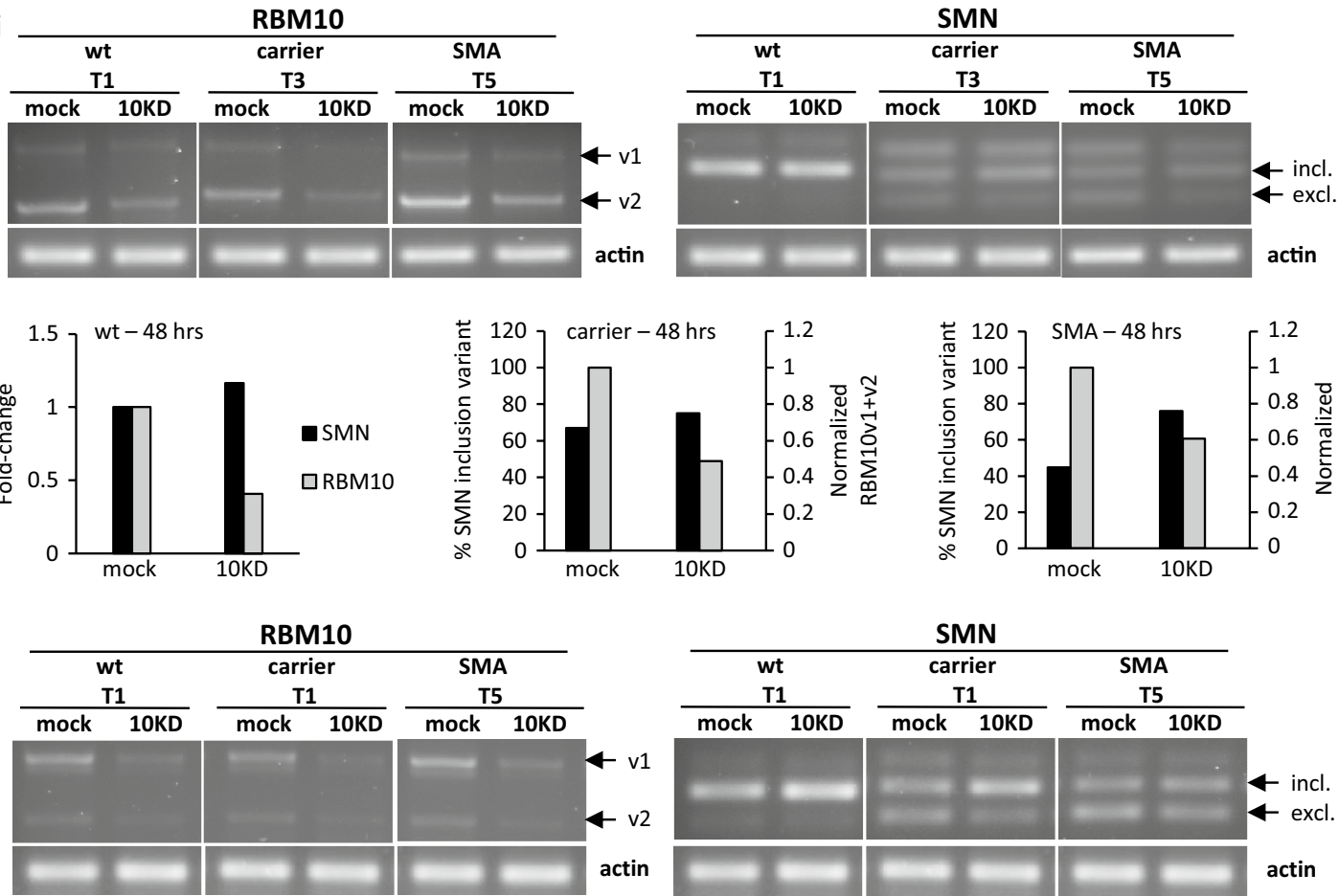

ii
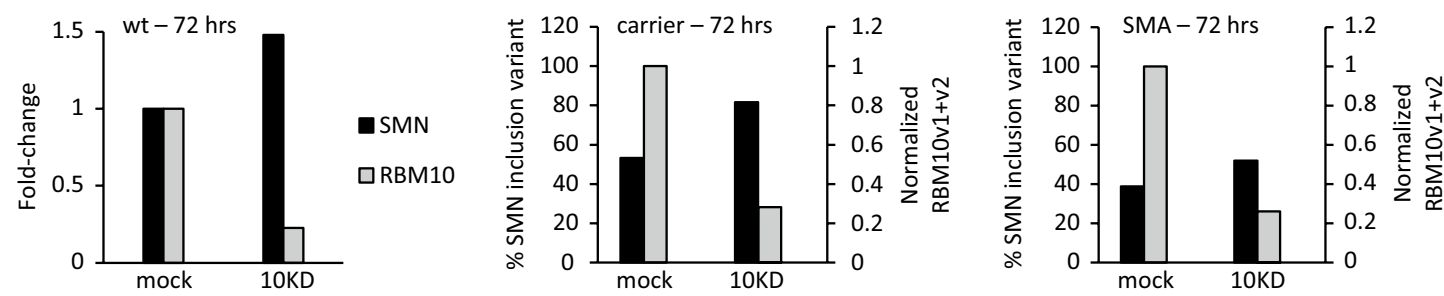

Fig. 5 SMN RNA expression in human fibroblasts following transient RBM10 KD. a RBM10 and SMN RNA expression in parental fibroblasts: (i) representative agarose gel following RT-PCR, and (ii) graphed densitometric data from $n=1$, representing the clearest data from the indicated transfections T2 and T4. T2 and T4 refer to two different transfections, numbered 2 and 4, respectively. $\mathbf{b}$ RBM10 and SMN RNA expression in mock transfected (mock) and RBM10 siRNA transfected (10KD) fibroblasts, $48 \mathrm{~h}$ following transfection. C RBM10 and SMN RNA expression in mock transfected and RBM10 siRNA transfected fibroblasts, $72 \mathrm{~h}$ following transfection. T1-T5 designate data from five different transfections. The RBM10 and SMN results presented for any particular time point and fibroblast type were from the same transfection

of expression of the inclusion to the exclusion bands increased in the RBM10 KD cells (Fig. 7cii). More surprisingly, in the stable RBM10 KD MCF-7 cells compared to the stable scrambled control subline, total expression of both isoforms increased an average of 2.5 -fold (Western blots of two biological replicates, one performed in 


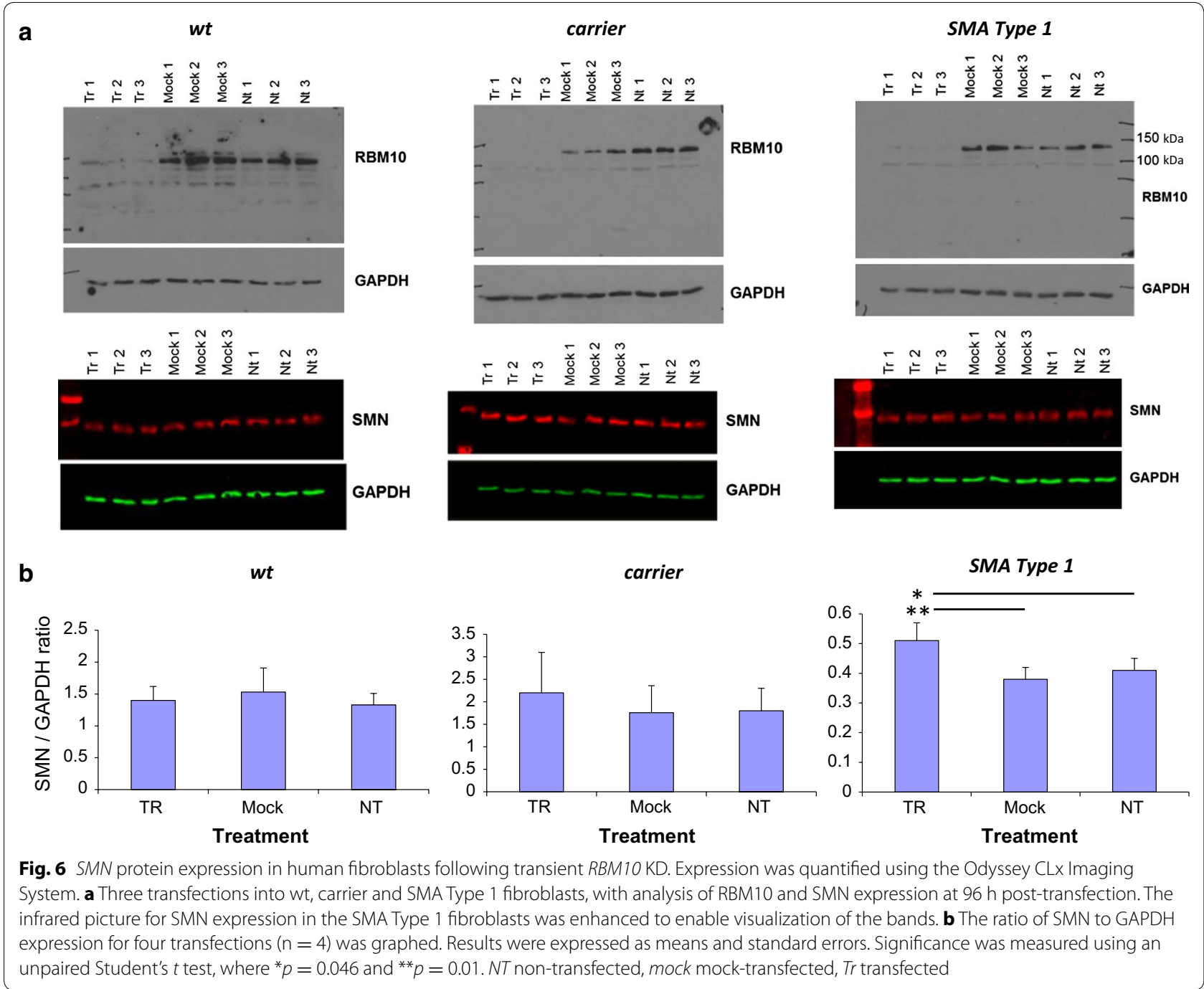

technical duplicate). These results suggest that long-term, stable, inhibition of RBM10, at least in MCF-7 cells, correlates with not only increased $\mathrm{SMN}^{\mathrm{FL}}$ expression levels, but stabilization of both SMN isoforms.

\section{Discussion}

When we began these studies, the only identified RBM10 RNA target was the transcript encoding the angiotensin 1 receptor (AT1). In rat vascular smooth muscle cells, RBM10 was shown to bind $A T 1$ mRNA in the $3^{\prime}$-untranslated region (UTR), resulting in message stabilization and modulation of transcriptional activity [5]. In that study, neither the RBM10 protein binding domain nor the AT1 RNA target sequence were defined. The findings presented in three more recent RBM10 studies $[2,3,6]$ expanded the number of RBM10 targets. The first study, using PAR-CLIP, overexpression, knockdown and RNA-Seq in HEK293 non-transformed, immortalized human embryonic kidney cells, was the first to demonstrate that RBM10 can indeed function to regulate alternative splicing, mediating preferential exon exclusion in a number of pre-mRNAs associated with TARP syndrome and cancer [3]. The second study, using a novel high-throughput screening strategy, demonstrated that RBM10 repressed Drosophila Dlg4 exon 18 pre-mRNA inclusion, thereby inhibiting synaptogenesis [6]. The third study, which used CLIP-Seq and splicing-sensitive microarrays with HeLa human cervical cancer cells, was the first to identify (1) RBM10 as a regulator of alternative splicing of the $\mathrm{NOTCH}$ signaling regulator $\mathrm{NUMB}$, in a cancer cell line, and (2) an RBM10 mRNA target binding motif [2]. Our findings are consistent with data presented in all three publications. 


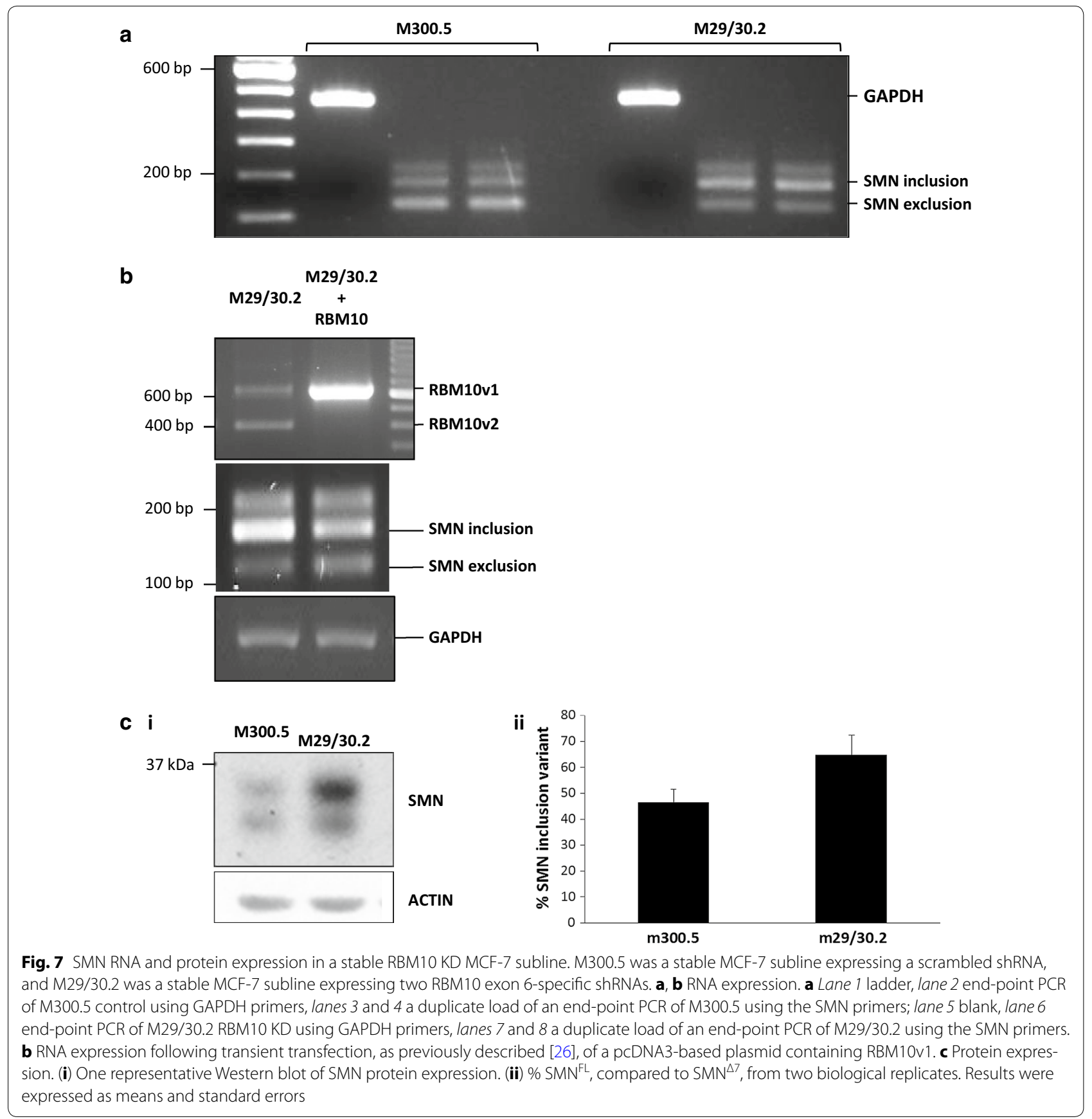

Firstly, our work demonstrates that downregulation of RBM10 expression correlates with substantial changes in the alternative splicing of a number of pre-mRNAs associated with cancer. For instance, KITLG [also termed "stem cell factor" (SCF) and "mast cell growth factor" (MGF)] is the ligand for the tyrosine kinase receptor c-KIT, involved in growth and development, particularly of haematopoietic and germ cells [27]. An exon 6-containing KITLG transcript encodes a precursor transmembrane form of the protein, which can be proteolytically cleaved within the exon 6 -encoded region to produce a secreted KITLG isoform [28]. This secreted KITLG isoform supports c-KIT tyrosine kinase activity less efficiently than the transmembrane form, and is mainly involved in stimulating cell proliferation. The exon 6-excluded alternate transcript, associated with wild-type 
RBM10 levels in our study, is incapable of producing the secreted isoform, since it lacks the metalloprotease cleavage site, and is therefore associated with more active c-KIT tyrosine kinase activity. In our study, KITLG exon 6 alternative splicing was investigated in five cancer cell lines. In two breast and one of two ovarian cancer cell lines having RBM10 KD, KITLG exon 6 was preferentially included, with normal RBM10 levels associated with exon 6 exclusion. Our findings suggest that, since RBM10 levels are increased in many cancers, $R B M 10$ may be a potential therapeutic target for those cancers harbouring elevated KITLG (such as many SCLCs [29, 30]).

Secondly, our work supports previous findings that RBM10 expression is most frequently associated with exon exclusion $[2,3,6]$. Notably, our work confirmed a previously identified association between $R B M 10$ expression and SIAHBP1/PUF60 exon 5 exclusion [3]. Both RBM10 and PUF60 are regulators of DLG4 exon 18 alternative splicing, which itself regulates synaptogenesis [6]. Normal levels of RBM10 are associated with PUF60 exon 5 exclusion, preferential DLG4 exon 18 exclusion and synaptic repression [6]. Interestingly, no consensus $R B M 10$ RNA binding motif, identified in a previous study [2], occurs around DLG4 exon 18, but does occur in PUF60 exon 5, suggesting that the regulation of DLG4 splicing by RBM10 may be an indirect effect that is mediated by the splicing factor PUF60 [31].

Thirdly, our work confirms that changes in RBM10 expression levels impact both cancer-associated and non-cancer-associated genes. We found that the most significantly affected signaling pathway resulting from $R B M 10$ inhibition was the $R A S$ signaling pathway, which is involved in the regulation of cell growth, differentiation and survival in all cell types. RAS proteins are small GTPases that transmit signals throughout the cell, turning on many genes involved in a range of processes. The five $R A S$ pathway associated genes, from Arrays-96 and -191 , that were affected by RBM10 inhibition, were a non-receptor tyrosine kinase $(A B L 2)$, a tyrosine kinase ligand (KITLG), a G-protein subunit (GNB3), a growth factor receptor (FGFR4) and a phospholipase (PLD1). Interestingly, recent work [32] showed that RBM10 interacted with the $R A S$ signaling associated protein FilGAP, a RAC-specific GTPase activating protein that regulates cell adhesion and migration. Our work therefore supports a potentially fundamental role for RBM10 in signal transduction regulation.

We also identified a novel role for RBM10, as a potential regulator of motor neuron function. One of three consistently altered splicing events that was observed in our arrays occurred in the SMN transcript. SMN codes for survival of motor neuron (SMN), a protein that is integral to the function of spinal motor neurons [33]. SMN protein is expressed at high levels in the brain, kidney, liver and spinal cord, moderate levels in skeletal and cardiac muscle and low levels in fibroblasts and lymphocytes [34]. In healthy individuals, $80-90 \%$ of SMN protein is coded by $S M N 1$, since a single nucleotide transition in the SMN2 gene exon 7 results in exclusion of exon 7 in the majority of expressed RNA, the production of a truncated protein $\left(\mathrm{SMN}^{\Delta 7}\right)$, and only a small amount of $\mathrm{SMN}^{\mathrm{FL}}$ produced from that locus. As a consequence, in individuals who have loss of SMN1 function (as in SMA Type 1 individuals), $\mathrm{SMN}^{\mathrm{FL}}$ encoded by $S M N 2$ cannot entirely compensate. Reduced $\mathrm{SMN}^{\mathrm{FL}}$ leads to a progressive degeneration of motor neurons, spinal muscular atrophy and eventual pulmonary failure [35]. The less $\mathrm{SMN}^{\mathrm{FL}}$ produced (related to $S M N 2$ gene copy number), the more severe the disease [36]. Regulators of SMN2 exon 7 alternative splicing include hnRNP G, hnRNP M, hnRNP Q, PSF, Sam68, SRSF1, SRSF9 and TRA2 $\beta$ [37-43] and another RBM10 target, PUF60 [31]. Binding of RBM10 to $S M N$ pre-mRNA was not found using PAR-CLIP in HEK293 cells [3], so any potential influence of RBM10 on $S M N$ alternative splicing might be indirect. As suggested for the regulation of $D L G 4$ alternative splicing (mentioned above), RBM10 associated regulation of SMN2 alternative splicing may occur through PUF60, since changes in PUF60 expression levels have previously been shown (in HeLa cells) to alter SMN2 exon 7 splicing [31].

\section{Conclusions}

In our study, because all of the cell lines examined showed increased expression of RNA encoding $\mathrm{SMN}^{\mathrm{FL}}$ following downregulation of RBM10, RBM10 may be a potential target for SMA therapy. The usefulness of our findings, with regards to SMA, would depend on the identification of an RBM10 antagonist that could specifically target motor neurons important to SMA, since downregulation of $R B M 10$ (particularly during embryonic development) is the causative agent for TARP syndrome $[9,10]$. The role played by RBM10 in TARP syndrome is unknown, but likely involves its ability to function as a splicing regulator [3]. The findings we report here suggest that TARP syndrome might be associated with not only dysfunctional RBM10 but elevated levels of either or both isoforms of SMN2. Since SMN ${ }^{\mathrm{FL}}$ is also involved in RNA processing, the relationship between $R B M 10$ downregulation, increased production of $\mathrm{SMN}^{\mathrm{FL}}$ and RNA processing in both TARP syndrome and SMA warrants further investigation. 


\section{Additional files}

Additional file 1. http://rnomics.med.usherbrooke.ca/ palace?purl=pcrreactiongroup/list/299. Genomics Platform-Palace: Overview Page.

Additional file 2. http://rnomics.med.usherbrooke.ca/palace?purl=data/ related/1811. Array-96--RBM10 Knockdowns in MCF-7, MDA-MB-231, SKOV-3, OVCAR-3 and PC-3.

Additional file 3: Table S1. Array-96: List of genes with changes, by cell line.

Additional file 4. http://rnomics.med.usherbrooke.ca/palace?purl=data/ related/2493. Array-191--RBM10 Knockdowns in BJ-TIELF, MCF-7, MDAMB-231, SKOV-3, and PC-3.

Additional file 5: Table S2. Array-191: List of genes with changes, by cell line.

Additional file 6: Figure S1. Verification of splicing changes in a stable MCF-7 RBM10 KD.

Additional file 7: Table S3. List of changes that occurred in cell lines common to both Array-96 and Arrar-191, and the GeneCard database designation used for pathway analysis.

\section{Abbreviations}

RBM10: RNA Binding Motif 10; SMN: survival of motor neuron; SMA: spinal muscular atrophy; ASE: alternative splicing event; KD: knockdown; $\triangle \psi$ : percent splicing index change; SMN ${ }^{\mathrm{FL}}$ : full-length SMN protein; SMN ${ }^{\Delta 7}$ : SMN protein with an exon 7 deletion.

\section{Authors' contributions}

BC, RKlinck and PT conceived the array assays. MD and EL performed the array assays. BC, RKlinck and PT interpreted the array data. LCS conceived the SMN experiments. $A B$ (under the supervision of RK) and LCS performed the SMN experiments. JK, JGR, SH, ST and JJL assisted with the SMN experiments. AB and LCS analyzed the SMN data, while RK and LCS interpreted the SMN data. IK (under the supervision of LS) carried out clustering and pathway analyses, and GY assisted with pathway analysis. LCS wrote the manuscript. LCS, BC, RK and IK reviewed the manuscript. All authors read and approved the final mauscript.

\section{Author details}

${ }^{1}$ Health Sciences North Research Institute, Sudbury, ON P3E 5J1, Canada.

2 Biomolecular Sciences Program, Laurentian University, Sudbury, ON P3E 2C6, Canada. ${ }^{3}$ Department of Chemistry and Biochemistry, Laurentian University, Sudbury, ON P3E 2C6, Canada. ${ }^{4}$ RNomics Platform of Université de Sherbrooke, Sherbrooke, QC, Canada. ${ }^{5}$ Ottawa Hospital Research Institute, Ottawa, ON K1H 8L6, Canada. ${ }^{6}$ Ontario Institute for Cancer Research, MaRS Centre, Toronto, ON M5G 0A3, Canada. ${ }^{7}$ Departments of Medicine and of Cellular and Molecular Medicine, University of Ottawa, Ottawa, ON K1H 8M5, Canada. ${ }^{8}$ Département de Microbiologie et d'infectiologie, Faculté de Médecine et des Sciences de la Santé, Université de Sherbrooke, Sherbrooke, QC, Canada.

\section{Acknowledgements}

Not applicable.

\section{Competing interests}

The authors declare that they have no competing interests.

\section{Funding}

This study was supported through funding from the Natural Science and Engineering Research Council of Canada Discovery Grant 9043429, Discovery Development Grant 00002 and the Northern Cancer Foundation (LCS), Ontario Ministry of Research, Innovation and Science (IK, LS), Muscular Dystrophy Association USA, Cure SMA and Canadian Institutes of Health Research (RK), and the Canadian Institute of Health Research (BC). BC is the Pierre C. Fournier Chair in Functional Genomics.

\section{Publisher's Note}

Springer Nature remains neutral with regard to jurisdictional claims in published maps and institutional affiliations.

Received: 15 May 2017 Accepted: 14 July 2017

Published online: 20 July 2017

\section{References}

1. Sutherland LC, Rintala-Maki ND, White RD, Morin CD. RNA binding motif (RBM) proteins: a novel family of apoptosis modulators? J Cell Biochem. 2005;94(1):5-24.

2. Bechara EG, Sebestyen E, Bernardis I, Eyras E, Valcarcel J. RBM5, 6, and 10 differentially regulate NUMB alternative splicing to control cancer cell proliferation. Mol Cell. 2013;52(5):720-33.

3. Wang Y, Gogol-Doring A, Hu H, Frohler S, Ma Y, Jens M, Maaskola J, Murakawa Y, Quedenau C, Landthaler M, et al. Integrative analysis revealed the molecular mechanism underlying RBM10-mediated splicing regulation. EMBO Mol Med. 2013;5(9):1431-42.

4. Wang K, Bacon ML, Tessier JJ, Rintala-Maki ND, Tang V, Sutherland LC. RBM10 modulates apoptosis and influences TNA-a gene expression. J Cell Death. 2012;5:1-19.

5. Mueller CF, Berger A, Zimmer S, Tiyerili V, Nickenig G. The heterogenous nuclear riboprotein S1-1 regulates AT1 receptor gene expression via transcriptional and posttranscriptional mechanisms. Arch Biochem Biophys. 2009;488(1):76-82.

6. Zheng S, Damoiseaux R, Chen L, Black DL. A broadly applicable highthroughput screening strategy identifies new regulators of Dlg4 (Psd-95) alternative splicing. Genome Res. 2013;23(6):998-1007.

7. Inoue A, Yamamoto N, Kimura M, Nishio K, Yamane H, Nakajima K. RBM10 regulates alternative splicing. FEBS Lett. 2014;588(6):942-7.

8. Tessier SJ, Loiselle JJ, McBain A, Pullen C, Koenderink BW, Roy JG, Sutherland LC. Insight into the role of alternative splicing within the RBM10v1 exon 10 tandem donor site. BMC Res Notes. 2015;8:46.

9. Johnston JJ, Teer JK, Cherukuri PF, Hansen NF, Loftus SK, Chong K, Mullikin JC, Biesecker LG. Massively parallel sequencing of exons on the $X$ chromosome identifies RBM10 as the gene that causes a syndromic form of cleft palate. Am J Hum Genet. 2010;86(5):743-8.

10. Gripp KW, Hopkins E, Johnston JJ, Krause C, Dobyns WB, Biesecker LG. Long-term survival in TARP syndrome and confirmation of RBM10 as the disease-causing gene. Am J Med Genet A. 2011;155A(10):2516-20.

11. Hernandez J, Bechara E, Schlesinger D, Delgado J, Serrano L, Valcarcel J. Tumor suppressor properties of the splicing regulatory factor RBM 10 . RNA Biol. 2016;13(4):466-72.

12. Furukawa T, Kuboki Y, Tanji E, Yoshida S, Hatori T, Yamamoto M, Shibata N, Shimizu K, Kamatani N, Shiratori K. Whole-exome sequencing uncovers frequent GNAS mutations in intraductal papillary mucinous neoplasms of the pancreas. Sci Rep. 2011;1:161.

13. Imielinski M, Berger AH, Hammerman PS, Hernandez B, Pugh TJ, Hodis E, Cho J, Suh J, Capelletti M, Sivachenko A, et al. Mapping the hallmarks of lung adenocarcinoma with massively parallel sequencing. Cell. 2012;150(6):1107-20.

14. Dilley WG, Kalyanaraman S, Verma S, Cobb JP, Laramie JM, Lairmore TC. Global gene expression in neuroendocrine tumors from patients with the MEN1 syndrome. Mol Cancer. 2005;4(1):9.

15. Rintala-Maki ND, Goard CA, Langdon CE, Wall VE, Traulsen KE, Morin CD, Bonin M, Sutherland LC. Expression of RBM5-related factors in primary breast tissue. J Cell Biochem. 2007;100(6):1440-58.

16. Galante PA, Sandhu D, de Sousa AR, Gradassi M, Slager N, Vogel C, de Souza SJ, Penalva LO. A comprehensive in silico expression analysis of RNA binding proteins in normal and tumor tissue: identification of potential players in tumor formation. RNA Biol. 2009;6(4):426-33.

17. Garrisi VM, Strippoli S, De SS, Pinto R, Perrone A, Guida G, Azzariti A, Guida $M$, Stefania T. Proteomic profile and in silico analysis in metastatic melanoma with and without BRAF mutation. PLOS ONE. 2014;9(12):e112025.

18. Venables JP. Aberrant and alternative splicing in cancer. Cancer Res. 2004;64(21):7647-54. 
19. Venables JP, Klinck R, Koh C, Gervais-Bird J, Bramard A, Inkel L, Durand M, Couture S, Froehlich U, Lapointe E, et al. Cancer-associated regulation of alternative splicing. Nat Struct Mol Biol. 2009;16(6):670-6.

20. Skotheim Rl, Nees M. Alternative splicing in cancer: noise, functional, or systematic? Int J Biochem Cell Biol. 2007;39(7-8):1432-49.

21. Venables JP, Koh CS, Froehlich U, Lapointe E, Couture S, Inkel L, Bramard A, Paquet ER, Watier V, Durand M, et al. Multiple and specific mRNA processing targets for the major human hnRNP proteins. Mol Cell Biol. 2008;28(19):6033-43.

22. Venables JP, Lapasset L, Gadea G, Fort P, Klinck R, Irimia M, Vignal E, Thibault $\mathrm{P}$, Prinos $\mathrm{P}$, Chabot B, et al. MBNL1 and RBFOX2 cooperate to establish a splicing programme involved in pluripotent stem cell differentiation. Nat Commun. 2013:4:2480.

23. Passini MA, Bu J, Richards AM, Kinnecom C, Sardi SP, Stanek LM, Hua Y, Rigo F, Matson J, Hung G, et al. Antisense oligonucleotides delivered to the mouse CNS ameliorate symptoms of severe spinal muscular atrophy. Sci Transl Med. 2011;3(72):72ra18.

24. Seo J, Singh NN, Ottesen EW, Lee BM, Singh RN. A novel human-specific splice isoform alters the critical C-terminus of Survival Motor Neuron protein. Sci Rep. 2016;6:30778.

25. Burnett BG, Munoz E, Tandon A, Kwon DY, Sumner CJ, Fischbeck KH. Regulation of SMN protein stability. Mol Cell Biol 2009;29(5):1 107-15.

26. Loiselle JJ, Tessier SJ, Sutherland LC. Post-transcriptional regulation of Rbm5 expression in undifferentiated H9c2 myoblasts. Vitro Cell Dev Biol Anim. 2016;52(3):327-36.

27. Chabot B, Stephenson DA, Chapman VM, Besmer P, Bernstein A. The proto-oncogene $c$-kit encoding a transmembrane tyrosine kinase receptor maps to the mouse W locus. Nature. 1988;335(6185):88-9.

28. Flanagan JG, Chan DC, Leder P. Transmembrane form of the kit ligand growth factor is determined by alternative splicing and is missing in the Sld mutant. Cell. 1991;64(5):1025-35.

29. Rygaard K, Nakamura T, Spang-Thomsen M. Expression of the protooncogenes c-met and c-kit and their ligands, hepatocyte growth factor/ scatter factor and stem cell factor, in SCLC cell lines and xenografts. Br J Cancer. 1993;67(1):37-46.

30. Heinrich MC. Is KIT an important therapeutic target in small cell lung cancer? Clin Cancer Res. 2003;9(16 Pt 1):5825-8.

31. Hastings ML, Allemand E, Duelli DM, Myers MP, Krainer AR. Control of premRNA splicing by the general splicing factors PUF60 and U2AF(65). PLoS ONE. 2007;2(6):e538.

32. Yamada H, Tsutsumi K, Nakazawa Y, Shibagaki Y, Hattori S, Ohta Y. Src family tyrosine kinase signaling regulates FilGAP through association with RBM10. PLOS ONE. 2016;11(1):e0146593.
33. Van Alstyne M, Pellizzoni L. Advances in modeling and treating spinal muscular atrophy. Curr Opin Neurol. 2016;29(5):549-56.

34. Coovert DD, Le TT, MCAndrew PE, Strasswimmer J, Crawford TO, Mendell JR, Coulson SE, Androphy EJ, Prior TW, Burghes AH. The survival motor neuron protein in spinal muscular atrophy. Hum Mol Genet. 1997;6(8):1205-14.

35. Lefebvre S, Burglen L, Frezal J, Munnich A, Melki J. The role of the SMN gene in proximal spinal muscular atrophy. Hum Mol Genet. 1998;7(10):1531-6.

36. Lefebvre S, Burlet P, Liu Q, Bertrandy S, Clermont O, Munnich A, Dreyfuss $\mathrm{G}$, Melki J. Correlation between severity and SMN protein level in spinal muscular atrophy. Nat Genet. 1997;16(3):265-9.

37. Hofmann Y, Lorson CL, Stamm S, Androphy EJ, Wirth B. Htra2-beta 1 stimulates an exonic splicing enhancer and can restore full-length SMN expression to survival motor neuron 2 (SMN2). Proc Natl Acad Sci USA. 2000;97(17):9618-23.

38. Hofmann Y, Wirth B. hnRNP-G promotes exon 7 inclusion of survival motor neuron (SMN) via direct interaction with Htra2-beta1. Hum Mol Genet. 2002;11(17):2037-49.

39. Young PJ, DiDonato CJ, Hu D, Kothary R, Androphy EJ, Lorson CL. SRp30cdependent stimulation of survival motor neuron (SMN) exon 7 inclusion is facilitated by a direct interaction with $\mathrm{hTra2}$ beta 1 . Hum Mol Genet. 2002;11(5):577-87.

40. Chen HH, Chang JG, Lu RM, Peng TY, Tarn WY. The RNA binding protein hnRNP Q modulates the utilization of exon 7 in the survival motor neuron 2 (SMN2) gene. Mol Cell Biol. 2008;28(22):6929-38.

41. Pedrotti S, Bielli P, Paronetto MP, Ciccosanti F, Fimia GM, Stamm S, Manley $J \mathrm{~L}$, Sette C. The splicing regulator Sam68 binds to a novel exonic splicing silencer and functions in SMN2 alternative splicing in spinal muscular atrophy. EMBO J. 2010;29(7):1235-47.

42. Cho S, Moon H, Loh TJ, Oh HK, Cho S, Choy HE, Song WK, Chun JS, Zheng $X$, Shen H. hnRNP M facilitates exon 7 inclusion of SMN2 pre-mRNA in spinal muscular atrophy by targeting an enhancer on exon 7. Biochim Biophys Acta. 2014;1839(4):306-15.

43. Cho S, Moon H, Loh TJ, Oh HK, Williams DR, Liao DJ, Zhou J, Green MR, Zheng X, Shen H. PSF contacts exon 7 of SMN2 pre-mRNA to promote exon 7 inclusion. Biochim Biophys Acta. 2014;1839(6):517-25.

\section{Submit your next manuscript to BioMed Central and we will help you at every step:}

- We accept pre-submission inquiries

- Our selector tool helps you to find the most relevant journal

- We provide round the clock customer support

- Convenient online submission

- Thorough peer review

- Inclusion in PubMed and all major indexing services

- Maximum visibility for your research

Submit your manuscript at www.biomedcentral.com/submit
() Biomed Central 